\title{
Modal Chromosome Number
}

National Cancer Institute

\section{Source}

National Cancer Institute. Modal Chromosome Number. NCI Thesaurus. Code C86971.

The most common chromosome number within a population or sample. 